\title{
Empirical Study of Effects on Energy Conservation by Industrial Structure Ad- justment in Beijing
}

\author{
Chunfang Zheng \\ Business College of Beijing Union University
}

\begin{abstract}
From 2000 to 2010, by increasing percentage of industries with low energy consumption intensity and decreasing that of industries with high energy consumption intensity, Beijing realized structural energy conservation and carbon emission reduction. After culculating by structural energy conservation formula, amount of energy conservation arising from structural adjustment is 1955.75 million tce during the $10^{\text {th }}$ five years and 5089.22 million tce during the $11^{\text {th }}$ five years. Amount of structural energy conservation is mainly from secondary industrial and tertiary industry and is not stable. There was a negative energy conservation in 2010. Therefore, it is necessary for Beijing to adjust industrial structure further.
\end{abstract}

Keywords: Industrial Structure Adjustment; Energy Conservation Effects; Amount of Structural Energy Conservation; Beijing; Empirical Study

Since 2000, energy conservation and carbon emission reduction has become consensuses in the world. China promised that carbon emission per GDP in 2010 should drop by 40 45\% compared that in 2005. During the $11^{\text {th }}$ five years, amount of drain contamination in China has dropped and realized the stage target. The target is to decrease energy consumption per ten thousands by about $20 \%$, to decrease water consumption per unit industrial value added by about $30 \%$, and to decrease main pollutants emission by $10 \%$ in 2010 than that in 2005. In this background, Beijing adjusted and optimized its industrial structure continously by accelerating eliminating industries with high energy consumption and emission. Since defferent industies had different energy consumption intensities, to adjust industrial structure, that is, to increase the percentage of industries with lower energy consumption intensity per unit value added than average level, and to decrease those with higher energy consumption intensity than average level, it helps realize structural energy conservation and emission reduction. This paper calculates changes of general energy consumption arising from industrial structure adjustment, analyzes reasons in order to provide some policy references for further industrial structure adjustment and emission reduction.

\section{Conditions for Classification for In dustries and Structural Adjustment}

In this paper, industrial structure is classified according to first industry, secondary industry and tertiary industry. Considering great difference of energy consumption and percentage of GDP, the secondary industry is divided into industry and building industry.

During the $10^{\text {th }}$ and $11^{\text {th }}$ five years, Beijing has insisted on adjusting industrial structure, cultivating actively Environmental protection industries, improv- 
ing tertiary industry. The percentage of tertiary industry in GDP rose from $64.8 \%$ in 2000 to $69.7 \%$ in 2005 and $75.1 \%$ in 2010. the percentage of seondary industry in GDP dropped from $32.7 \%$ in 2000 to $29.1 \%$ in 2005 and $24 \%$ in 2010 . And that percentage of first industry changed from $2.5 \%$ in 2000 to $1.3 \%$ in 2005 and $0.9 \%$ in 2010 . Meanwhile, inner stuctures of industry and the tertiary industry has changed continously. For example, percentages in manufacture industry of Ferrous Metal Smelting \& Rolling Processing Industry and communication equipment, computer\& other electronic equipment manufacture industry decreased from $14.03 \%$ and $16.69 \%$ in 2005 to $1.06 \%$ and $8.71 \%$ seperately. And the percentage in the tertiary industry of transportation industry, storage and the postal industry dropped from $8.31 \%$ in 2005 to $6.72 \%$ in 2010 , and percentage of value added of the wholesale and retail industry rised from $14.51 \%$ in 2005 to $17.81 \%$ in 2010.

\section{Calculation Amount of Structural Energy Saving}

Xiong Huawen(2011) gave the definition for amount of structural energy conservation, that is, amount of energy conservation arising from percentage changes of sub-systems in some industrial level. Suo Yujie(1984) put forward formula for calculating the amount of structural energy conservation for the first time, refer to formula (1), and emphasized percentages of the three industries in GDP and energy consumption intensity of unit industrial value added. Chen Shutong etc.(1996), Qi Baoping etc.(2010) and Xiong Huawen(2011) gave formula (2), and stressed that the industrial energy consumption intensity is the key factor of affecting the amount of industrial structural energy conservation. Zheng Dongli(2009) put forward formula (3), having added growth rates of GDP and value added of industry $j$. He believed that growth rate is the key factor affecting the amount of industrial structural energy conservation. Tinghua Climate Policy Research Center(2011) stressed the contributions arising from value added of industry $j$, industrial energy consumption intensity per unit value added, and comparison between growth rate of value added of industry $j$ and that of $G D P$ etc. refer to formula (4). This paper adopts formula (2) to calculate the mount of Structural Energy Conservation in Beijing during the $10^{\text {th }}$ and $11^{\text {th }}$ five years.

$$
\begin{aligned}
& \Delta E_{s t r j, t}=G D P_{t} \times \sum_{j=1}^{n j}\left(p_{j, t-1}-p_{j, t}\right) \times e_{j, t-1} \\
& \Delta E_{s t r, t}=G D P_{t} \times \sum_{j=1}^{n j}\left[\left(p_{j, t-1}-p_{j, t}\right) \times\left(e_{t-1}-e_{j, t-1}\right)\right] \\
& \Delta E s t r j, t=\sum_{j=1}^{n j}\left(e_{j, t-1}-e_{t-1}\right) \times\left[G_{j, t}-(1+k) \times G_{j, t-1}\right] \\
& \Delta E_{s t r j, t}=\sum_{j=1}^{n j}\left(e_{j, t-1}-e_{t-1}\right) \times\left(k_{j}-k\right) \times G_{j, t-1}
\end{aligned}
$$

Where, $\Delta$ Estr $_{j, t}$ means the amount of structural energy conservation in yeat $t$, $G D P_{t}$ represents GDP in year $t, p_{j, t}$ means percentage of value added of industry $j$ in GDP, $G_{j, t}$ represents value added of industry $j$ ( calculated at unchanged price), $e_{j, t}$ means energy consumption intensity per unit value added of industry $j$ in year $t$, its unit is tce/ten thousands, $e_{t}$ means energy consumption intensity per unit value added of all industries in year $t$, its unit is tce/ten thousands. $K$ is GDP growth rate, $k_{j}$ is growth rate of value added for industry $j$.

The paper adopts formula (5) to calculate the effects of percentage changes of three industries in GDP on $\mathrm{A}_{\mathrm{GDP}}$ (energy consumption per unit GDP), such as a decreasement by $1 \%$ of the percentage of 
industry in GDP and an increasement by $1 \%$ of the percentage of tertiary industry in GDP simutinously.

$\mathrm{A}_{\mathrm{GDP}}=\left\{\left[\mathrm{e}_{\text {生活 }}+\mathrm{e}_{\text {第一产业 }} \times \mathrm{p}_{\text {第一产业 }}+\mathrm{e}_{\text {工业 }} \times\left(\mathrm{p}_{\text {工 }}\right.\right.\right.$ 业 $-1 \%)+\mathrm{e}_{\text {建筑 }} \times \mathrm{e}_{\text {建筑 }}+\mathrm{e}_{\text {第三产业 }} \times\left(\mathrm{p}_{\text {第三产业 }}\right.$

$+1 \%$ ) $\left.] / \mathrm{e}_{\mathrm{GDP}}-1\right\} \times 100$

$\mathrm{A}_{\mathrm{GDP}}=\left[\sum_{i=1}^{n j}\left(\mathrm{p}_{\mathrm{j}, 2005}-\mathrm{p}_{\mathrm{j}, 2000}\right) \times\left(\mathrm{e}_{2005}-\mathrm{e}_{2000}\right)\right] /$

$\mathrm{e}_{\mathrm{GDP}, 2000} \times 100$

\section{Calcuation Results and Analysis}

Data used in the paper are from Beijing statistic yearbook and China energy statistic yearbook. Analysis of the $10^{\text {th }}$ and $11^{\text {th }}$ five years are based on unchanged price in 2000 and 2005 separately.

According to formula (2), energy conservation arising from industrial structural adjustment in Beijing is 1955.75 thousand tce during the $10^{\text {th }}$ five years, among which, amount of energy conservation in 2001 and 2002 were positive, and those in 2003 and 2004 are negative 630.40 thousand tce and negative 1141.29 thousand tce separately. Energy conservation arising from industrial structural adjustment in Beijing in the former 4 years of the $11^{\text {th }}$ five years are positive but that in 2010 is negative. Total energy conservation arising from industrial structural adjustment in Beijing in the $11^{\text {th }}$ five years is 5089.22 thousand tce. The energy conservation was mainly from structural adjustment of secondary industry and tertiary industry shown in fig. 1.

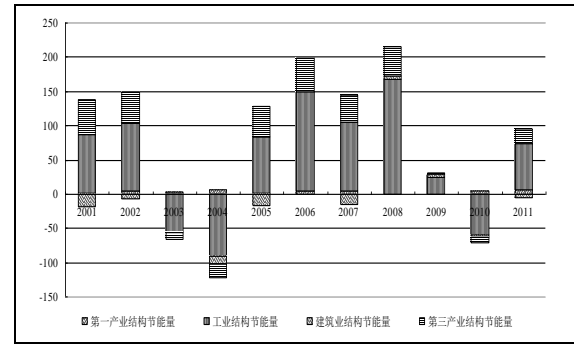

Fig. 1: Energy Conservation Arising from Industrial Structural Adjustment in Beijing During 2001-2011 unit: ten thousands tce

The calculating results of formula (5) show that effects on $\mathrm{A}_{\mathrm{GDP}}$ arising from percentage changes of different industries in Beijing are different. During the $10^{\text {th }}$ and $11^{\text {th }}$ five years, when the percentage of first industry in GDP decreased by $1 \%$ and that of tertiary industry increased by $1 \%$ simutinously, $\mathrm{A}_{\mathrm{GDP}}$ dropped by $99.981 \%$ and $99.994 \%$ separately. Fall percentage of $\mathrm{A}_{\mathrm{GDP}}$ when percentage of industry in GDP decreased by $1 \%$ and percentage of tertiary industry in GDP increased by $1 \%$ simutinously equals to that when percentage of first industry in GDP decreased by $1 \%$ and percentage of tertiary industry in GDP increased by $1 \%$ simutinously. It illustrates that effects on $\mathrm{A}_{\mathrm{GDP}}$ of structural adjustments of first industry and tertiary industry are same. Calculating results with formula (6) show that $\mathrm{A}_{\mathrm{GDP}}$ arising from percentage changes of the three industries in GDP in Beijing dropped by $84.08 \%$ in the $11^{\text {th }}$ five years, larger than a drop of $47.73 \%$ in the $10^{\text {th }}$ five years, and also different from a $1.64 \%$ increasement of $\mathrm{A}_{\mathrm{GDP}}$ arising from percentage changes of the three industries in GDP in China in the $11^{\text {th }}$ five years. Details are shown in table 1 . 
Table 1: Effects on $\mathrm{A}_{\mathrm{GDP}}$ Arising from Percentage Changes of the Three Industries in GDP in Beijing

$\begin{array}{|l|c|c|}\hline \multicolumn{1}{|c|}{\begin{array}{c}\text { Industrial } \\ \text { Structural } \\ \text { changes }\end{array}} & \multicolumn{2}{|c|}{\mathrm{A}_{\mathrm{GDP}} \text { change }} \\$\cline { 2 - 3 } $\left.\begin{array}{l}\text { A drops by 1\%, } \\ \text { D risesby 1\%. }\end{array} & -99.981 \% & -99.994 \% \\ \hline \begin{array}{l}\text { B drops by 1\%, } \\ \text { D risesby 1\%. }\end{array} & -99.981 \% & -99.994 \% \\ \hline \begin{array}{l}\text { A drops by 1\%, } \\ \text { B risesby 1\%. }\end{array} & -99.980 \% & -99.994 \% \\ \hline \begin{array}{l}\text { In the 10 } 10^{\text {th }} \text { five years: } \\ \text { A dropped by 1.2\%, }\end{array} & \multicolumn{2}{|}{} \\ \text { B dropped by 2.2\%, } \\ \text { C dropped by 1.4\%, } \\ \text { D rose by 4.9\%. }\end{array}\right)$

Note: In the table, A means percentage change in GDP of the first industry, $B$ means that of the secondary industry, $\mathrm{C}$ means that of the building industry, D means that of tertiary industry.

\section{Conclusion and Suggestion}

From the above calculation, the following conclusions can be drawn.

First, the energy conservation from structural adjustment in Beijing is mainly from secondary industry and tertiary industry.

Secondly, effects on $\mathrm{A}_{\mathrm{GDP}}$ in Beijing of structural adjustments of first industry and tertiary industry are same.

Thirdly, amount of energy conservation arising from industrial structural adjustment is not stable, with frequent fluctuations: a large amount of conservation in 2008 , a little amount in 2009 and a negative conservation in 2010. Therefore, further adjustment of industrial structure should be continued later.

\section{Acknowledgements:}

This paper is one of the output of the Funding Project for Academic Human Resources Development in Institutions of Higher Learning Under the Jurisdiction of Beijing Municipality.

Project No. PHR201008331.

\section{References}

[1] Qiye, "Blue Book of Low-Carbon Development2011-2012", Social Science Academic Press (China), pp.66-100,2011.

[2] Xiong Huawen, Methods for Analyzing Energy Conservation Potential and its Empirical Research Based on Energy Consumption of Per Unit GDP, Energy of China, 2011(4):2125.

[3] Qi Baoping, Mu Hailin, Kang Xudong, Wang Peng, Factor Analysis on 1990-2007 Energy Conservation in China, Energy Research and Management, 2010(2):1-4.

[4] Zheng Donglin, Shan Congli, Tao Jiangang, Analysis On How the Energy Conservation From Energy Consumption Construction Impacts the Energy Conservation Index, Shanghai Energy Conservation, 2009(10):18-22.

[5] Suo Yujie, Analysis on Calculation of Structural Energy Conservation, Conservation, 1996(5):2-8.

[6] Chen Shutong, Geng Zhicheng, Dong Luying, China's Energy and Economic Growth since 1990, Energy of China, 1984(4):113-118. 